\title{
Coautoría-responsiva y descripción densa: escritura investigativa en perspectiva analéctica-liberadora
}

\author{
Responsive co-authorship and dense description: investigative writing in an \\ analectic-liberating perspective
}

Solange Cárcamo-Landero (scarcamo@uct.cl) Facultad de Ciencias Sociales y Humanidades, Universidad Católica de Temuco (Temuco, Chile) ORCID: 0000-0003-4389-1096

Jorge Araya-Anabalón (jorge.araya@ufrontera.cl) Facultad de Educación, Ciencias Sociales y

Humanidades, Universidad de La Frontera (Temuco, Chile) ORCID: 0000-0003-0595-8114

\begin{abstract}
This paper proposes the possibility of a writing-authorship embodied in the understanding of socio-cultural diversity whose situational character favors the decolonization of research practices. For this purpose, is analyzed the writing stress that Clifford Geertz establishes between "being-there" ('writing in' the field), and "being-here" ('writing about' in the office). This stress is presented as part of a plot that connects the hermeneutic sense of geertzian dense description with Enrique Dussel's liberating analectic. Through this framework, "being-there" and "being-here" emerge as a space-time of writing opening which, by the word of others, becomes a responsive co-authorship.
\end{abstract}

Key words: scriptural praxis, co-authorship, epistemic decolonization, dense description, analectic.

\section{Resumen}

El artículo plantea la posibilidad de una escritura-autoría encarnada en la interpretación de la diversidad sociocultural, cuyo carácter situacional propicie la descolonización de las prácticas investigativas. Para ello, se analiza la tensión escritural que Clifford Geertz configura entre el "estar-allí" ('escribiendo en' el campo) y el "estar-aquí" (en el despacho 'escribiendo acerca de'). Esta tensión es propuesta como parte de una trama que enlaza el sentido hermenéutico de la descripción densa geertziana con la analéctica liberadora de Enrique Dussel. Mediante este entramado, el "estar-alli" y el "estar-aqui" emergen como espaciotiempo de apertura escritural que, gracias a la palabra ajena, deviene coautoría responsiva.

Palabras clave: praxis escritural, coautoría, descolonización epistémica, descripción densa, analéctica. 


\section{Introducción}

La configuración de prácticas investigativas descolonizadas constituye en Latinoamérica un reto ineludible para las ciencias humanas y sociales. Sobre este contexto, habitar la escritura y la autoría es un requisito fundamental para practicar pensamientos críticos y descoloniales que, efectivamente, permanezcan abiertos a la construcción de saberes liberadores. En este sentido, planteamos un análisis reflexivo acerca de la hermenéutica cultural de Clifford Geertz que, en diálogo con la analéctica liberadora de Enrique Dussel, busca situar la escritura-autoría en el horizonte de la descolonización epistémica. En consecuencia, asumimos la articulación de estas dos miradas distintas como una primera aproximación hacia lo que Silvia Rivera-Cusicanqui propone para superar la "esquizofrenia colonial", a saber: "Crear un campo de juego entre la herencia europea y la herencia propia [más la norteamericana, en este caso], en el que podamos, con autonomía recrear un pensamiento y un gesto capaz de superar el double bind" (Rivera-Cusicanqui, Domingues, Escobar y Leff 2016:4), que impide la construcción de una 'nueva ciencia social' entendida como 'una más de las ciencias de la vida'.

Precisamente, situar el pensamiento de Geertz en un horizonte descolonizador permite considerar que la interpretación de la diversidad sociocultural, la escritura de la voz ajena y el poder autorial, constituyen procesos entrelazados que atraviesan los distintos "campos de juego" de la investigación social. En efecto, en la hermenéutica cultural geertziana la escritura es interpretación profunda para comprender críticamente la otredad histórico-cultural y no simple escritura de las 'representaciones antropológicas' del otro. Al respecto, cabe precisar que Geertz comenzó sus trabajos en un clima intelectual que cuestionaba la posibilidad de comprender y describir, con palabras adecuadas, una cultura a la cual no se pertenece. Se trata de un cuestionamiento vigente, pero que hoy (en el campo de la descolonización epistémica) exige una escritura-autoría capaz de articular "la práctica de producir conocimiento que contribuya a transformar condiciones de opresión, marginación y exclusión de los estudiados y (...) [a su vez] la elaboración de análisis académicos más ricos y profundos con base en la experiencia de co-labor" (Leyva y Speed 2008:67). Ello implica una "confrontación que en la propia escritura deconstruya el discurso universal que borra sus condiciones de enunciación" (De la Peza 2012:21).

En esta dirección, proponemos una lectura situada del pensamiento geertziano, que busca reconocer el poder autorial de aquellos otros colaboradores (en adelante, 'sujetos-otros-conocidos') que, signados como "informantes clave", permanecen relegados en los espacios académicos hegemónicos. Así, al hablar de "sujetos-otros-conocidos" queremos enfatizar la (capacidad de) agencia de las comunidades investigadas y, al mismo tiempo, incorporar la epistemología del "sujeto conocido" que "viene a hablar allí donde la epistemología del sujeto cognoscente calla, mutila o limita" (Vasilachis de Gialdino 2006:51). En este sentido, hablamos de redescribir la escritura-autoría como praxis reconocedora del valor epistémico de la palabra ajena.

Como antecedente, cabe precisar que Geertz problematiza la relación entre investigación y autoría y la define como una tensión entre dos momentos-lugares característicos de la escritura etnográfica interpretativa: "entre «Estar-Allí y «Estar-Aquí» (...) entre el «Escribir En» y el «Escribir Acerca De» (Geertz 1997b:153). A partir de ello, articulamos esta tensión como parte de una trama que, al enlazar la descripción densa geertziana con el método analéctico Dusseliano, permite redescribir la escritura de la investigación social como coautoría responsiva. 
A lo largo del artículo hablamos de "redescribir" y, para ello, asumimos la hermenéutica ricoeuriana que considera "la referencia del enunciado metafórico en cuanto poder de "redescribir» la realidad" (Ricoeur 2001:12); lo que hace de la metáfora "una estrategia de discurso que, al preservar y desarrollar el poder creativo del lenguaje, preserva y desarrolla el poder heurístico desplegado por la ficción" (Ricoeur 2001:12). En este sentido, "redescribir" la escritura-autoría sería el resultado de una tensión relacional y existencial que viene a ampliar la comprensión del fenómeno escritural, recreando más plenamente su sentido y constituyéndolo en una nueva realidad. Ello significa que la escritura-autoría deviene no solo "modo nuevo de expresión"; sino, también, "ámbito nuevo" que dispone al sujeto para una nueva relación de sentido.

En el primer apartado planteamos que la escritura-autoría (investigativa) es parte constituyente de la descripción densa, es práctica incorporada en la interpretación inter-contextual de una cultura distinta a la propia. Hablamos de una escritura-autoría encarnada en la interpretación de la diversidad sociocultural, cuyo carácter situacional acentúa la reflexividad de las investigaciones sociales. Al explicitar el binomio escritura-autoría queremos subrayar la influencia que ejercen Barthes y Foucault en el pensamiento geertziano, especialmente, con respecto a una escritura que autoriza; que no solo "sostiene" una praxis, sino que la "constituye" y "funda discursividad". No obstante, con este binomio queremos transmitir, principalmente, la idea de oficio, de práctica como sabiduría incorporada que se ejerce. Así, mediante la imagen del oficio buscamos acercar la escritura-autoría investigativa a esa idea de "campo de transubjetividades en trayecto", en donde sí importa quién habla y quién calla, "un campo de transubjetividades que no termina nunca de fluir (...) como una trayectoria sin trayecto predefinido" (Mansilla-Torres 2013:44).

En el segundo apartado, las nociones "Estar Alli" y "Estar Aqui" emergen como antesala de descolonización epistémica, como lugares de enunciación que, si bien favorecen una escritura investigativa de apertura, permanecen en deuda con la palabra ajena. En este sentido, asumimos que "el objeto de investigación en las ciencias humanas" es "la palabra ajena" (Bajtín 1999:379). Desde esta palabra ajena -y no antes- surge el yo como subjetividad dialógica y polifónica que se construye desde la exotopía, desde la presencia de algo fuera del yo: el otro. Por lo que "Ser significa ser para otro y a través del otro, para sí mismo" (Bajtín 2015:163).

A partir de dicho planteo, en el tercer apartado, buscamos saldar la deuda que la escritura-autoría de las ciencias sociales tiene con la palabra ajena. Para ello, acudimos al método analéctico de Enrique Dussel que, como instancia creadora, transforma el "Estar Alli" y el "Estar Aqui" en un espacio-tiempo de apertura escritural. Desde este lugar, la descripción densa/escritura participaría de un proceso de descolonización epistémica que, gracias a la exterioridad, va revelando la negación que hacemos de la presencia autorial del Otro y, asimismo, va creando un lugar-otro de enunciación, más cercano a una ética de la responsividad.

Finalmente, concluimos que el cruce entre descripción densa, tensión escritural y analéctica permite concebir una coautoría responsiva que -como praxis escritural- se configura desde el contraste entre las condiciones espacio-temporales, propias y ajenas. Este contraste de temporalidades enlaza escritura y autoría como una praxis hermenéutica inter-contextual que contribuye a descolonizar la investigación social al situarla en un horizonte intercultural-crítico y liberador. 


\section{Situando la escritura/ interpretación en perspectiva inter-contextual}

Geertz señala que cuando un etnógrafo está investigando qué significa, 'desde el punto de vista de un nativo', ser 'una persona': “[El etnógrafo] se mueve desde un lado al otro preguntándose: «¿Cuál es la forma general de su vida?" y "¿qué son exactamente los vehículos en los que se encarna esa forma?», desembocando a su vez en el extremo de una especie de espiral similar, pertrechado con la noción de que ellos ven el self como un compuesto, como una persona, o como un punto en un mosaico" (Geertz 1994:89).

Esta es una referencia al círculo hermenéutico que nos dispone a reconocer que la investigación interpretativa de los fenómenos y procesos socioculturales conforma una "espiral hermenéutica" que entrelaza la anticipación de sentido (pre-comprensión) con el comprender lo otro en sus propios términos (Verstehen). En este sentido: "la noción de la espiral hermenéutica -de la anticipación del sentido a una comprensión más lograda, del encuentro entre nuestras preguntas iniciales con los referentes empíricos que llevan a respuestas modificadas al tomar en cuenta lo que los otros nos tienen que decir, de varias vueltas entre deducción e inducción-, es un camino epistemológicamente más sostenible y académicamente más fructífero" (Weiss 2017:652).

Así, la "especie de espiral" que Geertz describe permite vislumbrar que el diálogo con los 'sujetos-otrosconocidos' supone que el "carácter contextual de la aprehensión simbólica significa no tanto que ésta se halle determinada por el contexto en el que hace su aparición, como una referencia a sus potencialidades para crear contextos" (Costilla 2010:324). De hecho, Geertz plantea que la comprensión de otros pueblos "es más entender un proverbio, percibir una alusión, captar una broma -[...] leer un poema- que no alcanzar una extraña comunión con éstos" (Geertz 1994:90). Este planteamiento indica una disposición ético-epistémica y estética que asume que el símbolo "no es tanto un vehículo de sentidos múltiples, como de sentido, o de sentidos consistentes" (Costilla 2010:301). De lo que se deriva que comprender el sentido de los otros y de sus acciones requiere de una epistemología contextual que entiende el símbolo como elemento constituyente de reflexión participativa.

Desde esta perspectiva, el planteo geertziano previo remite a la crítica de Gadamer sobre el círculo hermenéutico como un movimiento que no se dirige a la mente del autor, sino al contexto (tradición) desde el cual dicho autor plantea sus opiniones. Así, Geertz se ubica en la perspectiva gadameriana según la cual "la comprensión no es nunca un comportamiento solo reproductivo, sino que es a su vez siempre productivo" (Gadamer 2003:366). Por ello, "Quizás no es correcto hablar de "comprender mejor» [...] Bastaría decir que, cuando se comprende, se comprende de un modo diferente" (Gadamer 2003:366). En efecto, en Geertz el trabajo interpretativo es oficio de traducción que no busca reproducir o revivir la vida ajena; sino reconocer el contexto singular desde el cual los otros expresan sus opiniones. Es decir, aprehender los modos de expresión de los Otros, su sistema de símbolos, para llegar a saber 'de qué están hablando'. Para ello, Geertz considera las acciones humanas como texto y enfatiza: "El etnógrafo «inscribe» discursos sociales, los pone por escrito, los redacta. Al hacerlo, se aparta del hecho pasajero que existe solo en el momento en que se da y pasa a una relación de ese hecho que existe en sus inscripciones y que puede volver a ser consultada" (Geertz 1997a:31).

Ahora bien, este trabajo interpretativo es la descripción densa que consiste en "establecer las significaciones que determinadas acciones sociales tienen para sus actores", "descubrir las estructuras conceptuales que informan los actos de nuestros sujetos, lo 'dicho' del discurso social” (Geertz 1997a:37). 
La descripción densa es, entonces, interpretar "el flujo del discurso social", "rescatar lo "dicho» en ese discurso de sus ocasiones perecederas" para "fijarlo en términos de consulta". Una tarea "microscópica" que busca "interpretaciones más amplias" (Geertz 1997a:32 y 33), partiendo del conocimiento de hechos pequeños, específicos y complejos, "hechos de contextura muy densa" (Geertz 1997a:38).

Aquí, cabe subrayar que Geertz reproduce la cita de Paul Ricoeur sobre la pregunta "¿Qué fija la escritura?": "No el hecho de hablar, sino lo 'dicho' en el hablar, [...] esa exteriorización intencional constitutiva de la finalidad del discurso gracias a la cual el sagen -el decir- tiende a convertirse en Aussage, en enunciación, en lo enunciado. En suma, lo que escribimos es el noema ('el pensamiento', el 'contenido', la 'intención') del hablar. Se trata de la significación del evento de habla, no del hecho como hecho" (Geertz 1997a:31).

La hermenéutica ricoeuriana -trasfondo de la descripción densa- permite esclarecer que observar, registrar y analizar (una cultura distinta) no son procedimientos separados; sino acciones entrelazadas que componen una sola tarea compleja y constitutiva de la descripción densa. Así, cuando Geertz plantea: "«¿Qué hace el etnógrafo?»: el etnógrafo escribe" (1997a:31); él está enfatizando que la escritura articula dichas acciones en una práctica unitaria que él denomina "escribir", "inscribir" o describir densamente. Sobre este contexto, decir que los investigadores sociales "escriben" no es un asunto tan sencillo, porque el observar, el registrar y el analizar se convierten en tres fases del conocimiento co-implicadas en la interpretación y descripción profunda de la diversidad sociocultural. A su vez, recordemos que: "la escritura [...] debe abrir en el texto mismo, de algún modo, un horizonte de interpretación y comprensión que el lector ha de llenar de contenido. "Escribir» es algo más que la mera fijación de lo dicho. Es cierto que la fijación escrita remite siempre a lo dicho originalmente, pero debe mirar también hacia delante. Lo dicho se dirige siempre al consenso y tiene en cuenta al otro" (Gadamer 2004:332).

Así, vemos que "escribir" es una práctica compleja. Más aún, si consideramos que la descripción densa/escritura no se realiza sobre "discursos sociales en bruto", sino desde una pre-comprensión que avanza hacia comprensiones más plenas. De este modo, el análisis cultural, entendido como descripción densa/escritura, involucra la acción de "conjeturar significaciones" y de "llegar a conclusiones explicativas partiendo de las mejores conjeturas" (Geertz 1997a:32). Este es el trasfondo desde el que Geertz plantea que la cultura 'es como' un texto enigmático, 'es como' un "documento activo" (Geertz 1997a:24) que tiene múltiples significados para sus actores. Entonces, "la cultura es un contexto" (Geertz 1997a:27), en el cual los investigadores se sitúan y desarrollan un oficio interpretativo de segundo orden, interpretación de interpretaciones. Al respecto: "Ios escritos antropológicos son ellos mismos interpretaciones y por añadidura interpretaciones de segundo y tercer grado. (... solo un "nativo» hace interpretaciones de primer orden: se trata de su cultura). De manera que son ficciones, ficciones en el sentido de que son algo "hecho», algo "formado», "compuesto» -que es la significación de fictio- no necesariamente falsas o inefectivas o meros experimentos mentales de «como si»" (Geertz 1997a:28).

Las interpretaciones de segundo orden, que realizan los investigadores, surgen desde el trabajo interpretativo realizado con los propios sujetos-otros-conocidos; lo que supone la construcción de un 'contexto de sentido de la acción', común a ambos interlocutores. La construcción de este nuevo contexto implica participar de "juegos lingüísticos (...) que nos permiten acceder a la comprensión del mundo en calidad de aprendices" (Gadamer 2003:584); ya que "el juego es para «distraerse», mientras todas las referencias finales que determinan a la existencia activa y preocupada (...) quedan de algún modo muy particular en suspenso" (Gadamer 2003:144). En este sentido, "la noción de juego (...) adquiere la 
condición de categoría que provoca «el descentramiento del sujeto» de la experiencia estética y a la larga de toda experiencia hermenéutica" (Monteagudo 2013:10). Así, las interpretaciones de segundo orden son experiencias de carácter inter-contextual que modifican a quienes las vivencian, pues emergen desde las intersecciones 'con-jugadas' entre dos lugares distintos; dos posiciones que desde la perspectiva geertziana denominaremos "«Estar-Allí» y «Estar-Aquí»" (Geertz 1997b:154).

Rescatar este carácter inter-contextual resulta decisivo para situar la escritura-autoría de las investigaciones sociales, ya que permite reconocer la cadena de interpretaciones en la que intervienen, activamente, los sujetos-otros-conocidos como agentes de sentido que construyen conocimiento local desde sus respectivos lugares de vida. Reconocer el carácter inter-contextual de la escritura-autoría investigativa abre la posibilidad de situar la investigación social en un lugar-otro; un lugar que, siguiendo a Arturo Escobar, implica un compromiso no-esencialista y crítico que permita defender política y epistemológicamente el conocimiento local. Al respecto, cabe precisar que: “Ciertamente, el 'lugar' y 'el conocimiento local' no son panaceas que resolverán los problemas del mundo. El conocimiento local no es 'puro', ni libre de dominación; los lugares pueden tener su propia forma de opresión (...); son históricos y están conectados al mundo a través de relaciones de poder (...). La defensa del conocimiento local (...) es política y epistemológica, y surge desde el compromiso con un discurso anti-esencialista de lo diferente" (Escobar 2011:147).

En este sentido, es necesario construir un lugar que reúna escritura y autoría como experiencias inseparables que se articulan a las prácticas interpretativas locales y a sus efectos de sentido. Al respecto, el sentido hermenéutico inter-contextual de la descripción densa exige una escritura-autoría compartida con los sujeto-otros-conocidos; dado que el arte de la interpretación (de segundo orden) se establece, al menos, entre dos agentes culturales distintos y dos lugares/momentos también distintos. Primero, la interpretación de la otredad emerge en la situación dialógica en la que el sujeto-otro-conocido, cara a cara con el sujeto-investigador, interpreta-narrando su historia (el "Estar Alli"). En esta situación la escrituraautoría deviene praxis, 'crea sentidos' que dan consistencia a la experiencia-vivida con los otros en el trabajo de campo. Segundo, la interpretación continúa en la situación de un diálogo introyectado cuando el sujeto-investigador-autor a partir de un diálogo interior, con sus notas de campo, rememora la experiencia de alteridad; pero en un contexto distinto en donde el sujeto-otro-conocido ya no está físicamente presente (el "Estar Aqui"). En este momento, la escritura-autoría se transforma en praxis si logra desentrañar las significaciones que adquiere el "Estar Aqui" 'escribiendo acerca de los otros', después de haber "Estado Alli" con ellos.

Si la descripción densa está constituida por los dos lugares/momentos escriturales antes descritos, entonces se requiere una escritura-autoría en movimiento capaz de situar la colaboración entre investigadores y "sujetos-otros-conocidos" en un horizonte inter-contextual más amplio, que posicione a ambos como coautores de una praxis interpretativa. Como veremos, este planteamiento implica comprender que la voz ajena y extraña de la alteridad igualmente "está aquí" (en la academia) cuando escribimos "acerca de". Y, efectivamente, está como "huella", como "presencia de una no-presencia", "presencia que esconde una ausencia de sentido "en sí»" (Sáez-Rueda 2009:441); pero, especialmente, está como exterioridad liberadora. 


\section{La "tensión escritural” como antesala de descolonización epistémica}

La tensión escritural entre el "Estar Alli" y el "Estar Aqui" puede ser leída como metáfora del lugar (o nolugar) que ocupa la otredad en la relación investigación-autoría. Ella evoca no solo la situación de los investigadores-autores; sino, también, la situación de inexistencia autorial en la que, generalmente, permanecen los 'sujetos-otros-conocidos' que testifican el carácter investigativo de un texto. La fuerza expresiva de esta 'metáfora' es aún mayor si consideramos que la textualidad científico-social actual, al estar centrada en "mostrar resultados", deviene ocultamiento de las circunstancias históricas bajo las cuales se escribe el texto de una experiencia investigativa compartida. En efecto, los 'sujetos-otrosconocidos' juegan un papel decisivo en la construcción de conocimiento; pero, habitualmente, se desconoce su derecho a la autoría.

En este contexto, la tensión escritural geertziana, interpretada como crítica a escrituras y autorías descontextualizadas, permite cuestionar la práctica habitual de recortar la palabra ajena según categorías pre-establecidas. Esta práctica de categorizar, muchas veces "está enmascarando situaciones de poder, que buscan mantener las desigualdades sociales" (Malik y Ballesteros 2015:23) y así olvidamos que "la propia categorización es un acto de poder" (Sánchez-Melero y Gil-Jaurena 2015:145). En este sentido, la tensión escritural geertziana expresa la dificultad para construir un "terreno común" (Geertz 1997b:154) entre el «Estar Allí» y el "Estar Aquí». Frente a ello, la crítica geertziana se alza en contra de autorías 'persuasivas' y 'difusas' que, basadas en 'ciertas pretensiones', se debaten entre posturas esteticistas y metodologicistas. Cabe detenernos en esta crítica porque tiene alcances neocoloniales que, finalmente, constituyen un obstáculo a la descolonización del estar aquí (en la academia).

En efecto, Geertz plantea que la autoría persuasiva se basa en demostrar que los investigadores-autores han estado allí y, a su vez, en convencer a los lectores de que ellos, si hubiesen estado allí, observarían exactamente lo mismo. Refiriéndose a esta "capacidad de convencer", señala: "Y en la persuasión de que este milagro invisible ha ocurrido, es donde interviene la escritura" (Geertz 1997b:14). En un contexto neocolonial, marcado por una concepción instrumental-designativa del lenguaje, dichas palabras imprimen a la autoría persuasiva un sello utilitarista que deforma las voces ajenas y su capacidad para engendrar conocimientos locales. En este escenario, la autoría persuasiva reproduciría la asimetría de poder que encubre la condición de agentes de sentido y de autores que tienen los 'sujetos-otrosconocidos'; pero también, aplacaría la capacidad socio-crítica de los lectores, al ubicarlos en una estética de la recepción pasiva. Así, la lógica de la persuasión es el correlato de una "epistemología del cazador" (Panikkar 2002:37) que confabula para "transportar" al lector hacia el lugar del otro. Bajo este influjo, la palabra ajena es utilizada solo como defensa autorial de los investigadores. Si, mediante ello, los lectores quedan convencidos de que 'han habitado' ese otro lugar, que 'han comprendido' la vida ajena; entonces, se cierra el círculo del reconocimiento deformado.

A ello se suma la advertencia geertziana que indica que la investigación de la diversidad cultural emerge desde relatos aislados que se encuentran al remover la dramática contingencia de la cotidianeidad. Al respecto, Geertz busca una autoría responsable, capaz de asumir que el tiempo vivido con la otredad ("Estar Alli") no es un tiempo que fluye como un 'río' armonioso que desemboca en el 'mar' o como una “ola compleja que un analista armónico pueda descomponer en factores" (Geertz 1996:12). Así, la autoría responsable geertziana asume que no existe una historia general que contar, sino solo conglomerados de historias que intentan expresar fenómenos culturales. 
Si asumimos esta advertencia, pero continuamos operando con la lógica instrumental-designativa, fácilmente podemos transitar hacia autorías difusas; en cuya práctica no se sabe quién es el que autoriza y qué es lo que finalmente se autoriza. Esta es una crítica a una autoría que -hablando por otros- no se hace responsable de sus dichos y efectos, pero insiste en 'persuadir' a los lectores. En estas circunstancias, el otro sigue siendo objeto (y no sujeto-agente) de la escritura, ahora fragmentada. Así, las autorías persuasivas y difusas reproducirían las lógicas monoculturales de "producción de ausencias o noexistencias" (Santos 2011:30); ya que desconocerían la emergencia de sujetos-actores que, actualmente, buscan descolonizarse en el campo social con sus propios lenguajes y textos. En clave geertziana, desconocerían, asimismo, que las actuales transformaciones del "contexto moral" -en el que tiene lugar el acto de la 'escritura-autoría'- han modificado el supuesto de que "sus sujetos y su público" sean "separables" o estén "moralmente desconectados", "que los primeros tenían que describirse pero no ser interpelados, y los segundos informados pero no implicados" (Geertz 1997b:142).

En este contexto, "la construcción imaginativa de un "terreno común" ["conexión textual"] entre el "Escribir En" y el "Escribir Acerca De" (Geertz 1997b:154), significa re-describir un lugar escritural nodicotómico, mediante investigaciones horizontales basadas en el diálogo y la reciprocidad. Ello es necesario porque aún prevalecen algunas presunciones -la "ventriloquía etnográfica" (Geertz 1997b:154), por ejemplo- que niegan la 'complejidad discursiva' y reproducen las 'asimetrías morales'. Asimismo, dicha redescripción escritural es necesaria, porque "los "Allí» y los "Aquí» están hoy mucho menos aislados... (aunque lo están profundamente a la vez)” (Geertz 1997b:157).

La crítica anterior implica la descolonización del 'Estar Aqui' (academia) después de haber 'Estado Alli'. Ello ocurriría mediante prácticas inter-contextuales que eviten el centrismo epistémico al enfocar "la reflexividad como des-centramiento" (Gambarotta 2014:20). Cabe subrayar que el des-centramiento de la propia mirada deviene proceso de toma de conciencia de las condiciones sociales de producción del conocimiento; proceso potencialmente liberador de los condicionamientos epistémico-políticos que constriñen a los investigadores. La reflexividad constituye, entonces, una tarea político-epistémica central para "evitar la tendencia intrínseca a legitimar -aun cuando no se lo busque- las relaciones de dominación hoy establecidas" (Gambarotta 2014:23).

No obstante, la reflexividad pareciera interrumpirse cuando los investigadores "deben" publicar sus hallazgos. En este punto, la reflexividad debe enfocarse en el estar aquí (en la academia), en el acontecer del lenguaje científico convencional, que recobra su poder instituyente al reproducirse como "lenguaje común", cotidiano, entre colegas-investigadores. Reaparece, así, el riesgo de caer en un esteticismo o metodologicismo de la escritura-autoría; dado que el "lenguaje común" de la academia condiciona la escritura investigativa según sus propios cánones. Frente a este condicionamiento, la descolonización del estar aquí exige que el sujeto des-centrado incorpore una estética-crítica de la escritura. Al estar aquí, 'escribiendo acerca de', necesitamos una estética incorporada a la investigación social, cuyo propósito sea remitirnos al dialogismo de la 'palabra ajena'. Recordemos que la escritura es, para Bajtín, comunicación discursiva de segundo orden. Al respecto: "Bajtín habla de la palabra escrita solo en una segunda instancia, partiendo de la comunicación oral, y en la escritura resuenan, para él, de un modo virtual, pero semióticamente perceptible, las voces de las otras personas, de opiniones, de posiciones individuales y de grupos sociales" (Bubnova 2006:101).

Desde esta perspectiva, la escritura investigativa deviene "acto ético responsable" (Bajtín 1997:24); acto que involucra un diálogo 'tú-yo' que, intuitivamente, debe aceptar a un tercero; cuya presencia implica 
apertura, riesgo y responsabilidad. Geertz sintoniza con este planteamiento, particularmente, cuando señala que el propósito de la escritura investigativa "no es dar respuesta a nuestras preguntas más profundas, sino darnos acceso a respuestas dadas por otros, que guardaban otras ovejas en otros valles" (Geertz 1997a:40); y, mediante ello, ampliar el registro consultable de lo humano. En otras palabras, dicho propósito es contribuir a "la ampliación de las posibilidades del discurso inteligible entre gentes tan distintas entre sí en lo que hace a intereses, perspectivas, riqueza y poder, pero (...) sumidos en una interminable red de conexiones" (Geertz 1997b:157).

No obstante, para evitar el esteticismo neocolonialista necesitamos asumir el carácter éticopolítico/transformador de la escritura-autoría científica; lo que implica develar la normalización de las relaciones de dominación establecidas, comenzando por aquellas que emergen entre el 'trabajo de campo' (el Estar Allí) y el 'despacho' (el Estar Aqui). Si la escritura-autoría es algo más que "mera seducción verbal: un artificio retórico destinado a mover mercancías intelectuales en un mercado competitivo" (Geertz 1997b:152); entonces, preguntar por sus 'efectos' y 'como' los produce, no puede ser "una cuestión marginal, minimizada por los problemas de método y las discusiones teóricas” (Geertz 1997b:158).

Geertz se acerca a resolver este problema al plantear que la "tensión escritural" involucra asumir responsablemente que la escritura es "arte" que trasciende la instrumentalización, que "no hay forma de evadirse del peso de la autoría, (...) de desplazar esta responsabilidad" (Geertz, 1997b:149). En este sentido, habla de "una escritura imaginativa sobre gentes reales en sitios reales y tiempos reales" (Geertz 1997b:151) y, en consecuencia, de un escritura-autoría investigativa que busca "inscribir un presente, transmitir con palabras «cómo es» estar en algún lugar concreto de la cadena vital del mundo: Aquí, como dijo Pascal, en vez de Allí; Ahora, en vez de Entonces. (...) traslación de lo actual, vitalidad traducida en palabras" (Geertz 1997b:152).

Sin embargo, debemos subrayar que la responsabilidad autorial se ejerce en un contexto ('Estar Aqui' en la academia) de políticas textuales atravesadas por distintas lógicas de dominación. Una de estas, es la "lógica del tiempo lineal" -del tiempo y ritmo de la producción neoliberal- que desconoce distintas temporalidades al basarse en "una concepción del tiempo presente que lo reduce a un instante fugaz entre lo que ya no es y lo que aún no es" (Santos 2005:158). Esta lógica de dominación perturba el ritmo de las conversaciones, niega la posibilidad de un diálogo deliberativo con los sujetos-otros-conocidos y, así, reproduce socialmente su ausencia. En este sentido, "los nuevos problemas que orientan la producción del saber, surgen desde la necesidad de ampliar el presente (...) parten del inconformismo ante el desperdicio de experiencia y ante la carencia de posibles futuros emancipatorios" (Binimelis-Espinoza y Roldan-Tonioni 2017:225).

Si asumimos la tensión escritural (Estar allí versus estar Aquí) como una experiencia de apertura hermenéutica que dilata el presente, entonces se abre un espacio-tiempo para transformar las ausencias en presencias, para crear un contexto de escritura en donde la temporalidad es otra. Este sería un momento de apertura o desprendimiento epistémico que redescribe el "Estar Aqui" (en la academia) en los términos de un co-presente especioso, una especie de presente vívido que entrelaza el pasado de las memorias ("estuve allí con los otros") con el futuro utópico de lo distinto. Con ello, contribuye a incorporar "una copresencia radical [que] significa que las prácticas y los agentes de ambos lados de la línea son contemporáneos en términos iguales" (Santos 2010:32). Así, la mirada epistémica se sitúa desde el lado de la experiencia social de los otros que "están allí" y que emergen como contemporáneos a la academia. Desde este co-presente especioso, la escritura-autoría investigativa puede dirigir su atención hacia las 
ruinas reveladoras de las más sutiles contradicciones y asimetrías que ocurren entre el trabajo de campo (Estar Allí) y la academia (Estar Aquí). En este sentido, la escritura-autoría deviene espacio-tiempo de transformación de subjetividades en juego que, gracias al contraste de temporalidades distintas, hace posible un horizonte-otro de inteligibilidad.

Si nos situamos en este co-presente especioso, la tensión escritural aparece como antesala de descolonización epistémica, es decir, como lugar que predispone hacia una hermenéutica diatópica orientada a superar la distancia epistemológica y humana; distancia que "no es meramente temporal, dentro de una única y amplia tradición, sino que es la distancia que existe entre dos topoi humanos, «lugares» de comprensión y autocomprensión, entre dos (o más) culturas que no han elaborado sus modelos de inteligibilidad o sus premisas fundamentales a partir de una tradición histórica común o mediante una influencia recíproca" (Panikkar 2007:33).

Cabe precisar que se trata de una tercera hermenéutica, distinta a las hermenéuticas morfológica y diacrónica, cuyo olvido ha generado incomprensión intercultural. En este sentido, es necesario esclarecer que hablamos de la tensión escritural como antesala de descolonización epistémica, porque la hermenéutica diatópica -hacia la que predispone- es una filosofía intercultural que "debe asumir el reto de proponer modelos de argumentación intercultural, teniendo en cuanta las necesidades y contextos particulares en los que el diálogo es requerido" (Gómez 2015:42). Sin embargo, si consideramos que "La traducción entre saberes asume la forma de una hermenéutica diatópica. (...) que hace posible la ecología de saberes" (Santos 2011:37), entonces dicha predisposición hermenéutica puede reorientar la escrituraautoría investigativa hacia la descolonización epistémica. Esta, en la trayectoria filosófica y epistemológica aquí esbozada, emerge como auto-crítica cultural de la 'función-autor' ('identidad textual', 'firma') y del 'discurso' ('qué es lo que se autoriza'); autocrítica que, para ser radical, necesita emerger desde la apertura a una realidad-otra que provoca: apertura a una exterioridad que interpela.

\section{Estar Allí y Estar Aquí en perspectiva analéctica}

La tensión escritural entre el "estar alli" y "estar aquí" remite a la historicidad como elemento constitutivo del modo en que conocemos/concebimos la diversidad sociocultural. En efecto, Geertz se pregunta cómo "meter «sus» vidas -la vida de los otros- en «nuestras» obras", si ahora ya sabemos que no solo se trata de una "dificultad técnica", sino de "un asunto moral, político e incluso epistemológicamente delicado" (Geertz 1997b:140). Este cuestionamiento implica que la alteridad ya no puede ser re-presentada en un simple relato. Por el contrario, se requiere una escritura-autoría esclarecedora de las condiciones de producción de la textualidad científica y del lugar político-epistémico desde el cual se describe 'la vida de los otros'.

No obstante, descolonizar la "responsabilidad autorial" significa transparentar la dialogía de una autoría compartida. Para ello, hablamos de una escritura-autoría de apertura (inacabada) que en clave analéctica liberadora permita superar la violencia epistémica que acontece cada vez que -entre el estar allí y el estar aquí- terminamos por encubrir la palabra ajena. En este sentido, el método analéctico de Enrique Dussel es condición de posibilidad para situar las interrogantes geerztianas en un horizonte ético-político y epistémico liberador. Como "momento de afirmación de la exterioridad" (Dussel 2011:240) dicho método permite profundizar la idea geertziana de la escritura como arte que responsablemente asume el peso de la autoría. En este sentido, la analéctica sitúa la descripción densa/escritura en el campo de una praxis escritural transformadora. 
El planteamiento anterior es posible porque la analéctica es praxis liberadora y creadora de conocimientos que emergen desde la "palabra del Otro". Esta palabra "irrumpe siempre como interpelación (...) desde más allá de la totalidad, como lo que todavía no tiene sentido, porque justamente está más allá de todo sentido" (Dussel 1995:120). Así, la palabra de los Otros es pura exterioridad que exige una hermenéutica de apertura-otra, un habitar el mundo irreductible de la otredad-distinta.

Dussel habla de una palabra interpelante que viene a 'mi' desde una exterioridad, es decir, desde un ámbito que está fuera de los fundamentos del mundo (racionalidad totalizadora). Entonces, ella aparece como algo que no puedo comprender, le niego su ser y la transformo en pura negatividad. Sin embargo, cuando el "camino" (método) deviene analéctico, cuando el punto de partida es el Otro como oprimido; nuestro 'caminar' se "detiene ante el otro como un rostro de misterio y libertad, de historia dis-tinta" (Dussel 1995:233). Aquí, comenzamos a escuchar aquella palabra-otra que es "dis-tinta" y no "di-ferente"; "aquello que es desde siempre "otro"" (Dussel 1995:233), que no puede diferir o diferenciarse porque no corresponde a la dualidad identidad/diferencia que constituyen dos modos (similares) dentro de la totalidad.

Mediante estos postulados analécticos, la escritura-autoría científica puede sobreponerse a la lógica de las ausencias y al consecuente "desperdicio de experiencias sociales" (Santos 2006:19). Cuando la escritura es construida socialmente como ausencia (sin valor epistémico-político liberador), es necesario recordar que el oficio reflexivo de la praxis-escritural es parte del proceso constituyente de (inter)subjetividades emergentes. En este proceso, la escritura-autoría se hace partícipe de la extrañeza de las voces ajenas que van emergiendo. Incluso, su propio carácter ético-político emerge desde una sensibilidad que reconoce esa 'extrañeza del otro' como 'extrañeza de uno mismo'. Desde este ámbito -de voces extrañas en juegoel reconocimiento del lenguaje ajeno redescribe la escritura-autoría como co-labor que siempre remite y responde a ese juego. En este sentido, la analéctica permite asumir la escritura-autoría como oficio reflexivo emergente; oficio que no se separa de la construcción de conocimiento científico; sino, por el contrario, "pone de relieve el carácter situado de la escritura científica" (Valenzuela 2014:106) y "la naturaleza constitutiva de la escritura en tanto escenario de creación" (Valenzuela 2014:107).

Con respecto al punto anterior, la analéctica desempeñaría un rol importante al transformar la responsabilidad autorial en lo que definiremos como coautoría responsiva. Para ello, acudimos a Bernhard Waldenfels y su texto "Respuesta a lo extraño. Rasgos fundamentales de una fenomenología responsiva". Desde esta perspectiva, la coautoría responsiva sería una autoría compartida y participativa "que empieza más allá del sentido y de las reglas, allí donde algo nos desafía y pone en cuestión nuestras propias posibilidades, antes de que nosotros nos embarquemos en una inquisitiva voluntad de saber y de comprender" (Waldenfels 1997:22). Así, el responder es siempre una respuesta a lo extraño, acto/expresión que involucra singularidad, ineludibilidad, posterioridad y asimetría; cualidades que nos reconducen a la propuesta bajtiniana de un diálogo ontológico como acto ético/responsable, arriesgado, abierto y participativo; acto atravesado por la responsividad. Aquí, cabe precisar que la extrañeza o "Io extraño" es un "elemento constitutivo de la experiencia. (...) [es] "accesibilidad... de lo que es originalmente inaccesible»" (Waldenfels 2017:421). Al respecto: "Esta inaccesibilidad no excluye que lo propio y lo extraño interactúen uno en otro en forma de un entrelazamiento recíproco, así por ejemplo (...) en el cambio de palabras en el que, según Michail Bachtin, la palabra propia forma una «palabra semiextraña», puesto que esta está ocupada continuamente con intenciones extrañas y se "mueve en la frontera entre lo propio y lo extraño» (Waldenfels 2017:421). 
Tanto la fenomenología responsiva como el diálogo ontológico hablan de un acto responsable que sintoniza con la analéctica dusseliana, especialmente, al compartir la exigencia de responder a algo distinto que está más allá del "yo", a algo irreductible, a la extrañeza. En este sentido, "lo extraño" contiene un potencial liberador: "la extrañeza no es sacrificada a una totalidad institucional o lingüística ya existente. (...) la extrañeza y la renuncia a su incorporación violenta ofrecen también una resistencia contra tentaciones totalitarias en la política" (Waldenfels 2017:421). Así, hablamos de una coautoría que responde críticamente a prácticas investigativas que emergen desde el mundo de la otredad-distinta; otredad-extraña que, pese a ser silenciada, irrumpe para expresar que el lenguaje es experiencia de alteridad, extraña y compleja.

No obstante, para que dicho carácter responsivo encarne, efectivamente, el principio exterioridad (la alteridad-negada por la totalidad) debe fundarse en un trabajo analéctico liberador, que exige salir a la intemperie para escuchar y comprometerse con la palabra del Otro. Al respecto Dussel advierte que: " "Liberación» como "trabajo» es estrictamente el acto transontológico del que en la totalidad escucha la palabra de Otro (que irrumpe como interpelación desde más allá del sistema, cuestionándolo) y se juega por él. Ahora, el que se juega por el Otro como el hebed, termina por ser perseguido, que se avanza como el rostro del hombre ante el cual todos vomitan, escupen y se ríen, porque habiendo franqueado el muro de la ciudad se queda a la intemperie" (Dussel 1995:132).

Frente a esta advertencia, la coautoría responsiva surge desde el "trabajo de campo" ("Estar alli") entendido como trabajo de liberación que implica reflexión político-epistémica y existencial, compartida con los sujetos-otros-conocidos. Ello es posible porque ante la interpelación de la otredad distinta y extraña, el "temor al relativismo" -el miedo a la co-construcción pluralista del mundo- emerge como temor colonialista: temor a la extrañeza de la voz ajena que ya habita en 'mi'. Así, el principio exterioridad permite reconocer aquella voz ajena como presencia-ausente de un tercero; un Otro que escapa a la escritura, pero que es (y siempre ha sido) coautor de una praxis escritural que es crítica a lo establecido. En este sentido, la coautoría responsiva trabaja con el Otro-negado reconociéndolo como ser autónomo e independiente, es decir, reconociendo sus lógicas de negación y, por lo tanto, su presencia irreductible a una escritura totalizadora, que solo mira lo real medible.

Así, la transformación de la escritura-autoría emerge desde el Otro que se expresa desde su exterioridad (su vida, su historia) que me es ajena y, en consecuencia, "la única manera de interpretarlo plenamente es acceder hasta su ámbito" para lo cual "primero, tengo que creer, por fe en lo que me dice" (Dussel 1995:235). La coautoría responsiva nacería, entonces, desde una palabra histórica que, siguiendo a Dussel, no se 'verifica' a priori sino solo a posteriori, en la historia; es decir, en la temporalidad, en el convivir con el Otro. Solo de este modo, se deshace el temor colonialista al relativismo y se abre un camino para el despliegue de la imaginación político-epistémica.

Con respecto al punto anterior, cabe precisar que "la praxis de liberación como actualidad creadora" (Dussel 2014:156) de un nuevo orden, tiene un carácter ético crítico que implica no solo deconstruir un orden éticamente injusto y malo (momento normativo deconstructivo), sino también participar de un momento creador en el cual la creación se entiende como el avance de la historia humana. Al respecto: "EI nuevo orden toma algo del antiguo, y por ello es también trans-formación (cambia cierta forma), pero en su núcleo esencial y sustantivo es nuevo, surge desde la exterioridad del Otro (nada del sistema) y pone en la existencia nuevas relaciones práctico institucional que no estaban en potencia (eran imposibles) para las instituciones antiguas vigentes. Hay entonces subsunción de algunos aspectos del orden que se supera, 
y puesta en existencia de aspectos nuevos operados desde la nada (del antiguo sistema): creación transformativa entonces" (Dussel 2014:155).

En este sentido, la coautoría responsiva asume que la otredad-distinta no es una cosa funcional dentro de un sistema, sino una existencia anterior que permite deconstruir el substrato ético-moral establecido. Así, la exterioridad es esa voz extraña que permite a la coautoría hacerse responsiva; porque es su presenciaausente la que permite de-construir el carácter instrumental estratégico de la escritura-autoría instituida. A su vez, ella muestra que el problema ya no es escribir la vida ajena en "mi" texto como "realidad acabada o parcial"; sino crear con la otredad-distinta un nuevo orden escritural en el que la propia escritura sea "actualidad creadora". Ello implica no solo destruir lo incorrecto/injusto de una escritura-autoría establecida (ajustes al sistema); sino avanzar en la construcción de un orden autorial enfocado en afirmar y hacer crecer la autoría de los otros que no han sido reconocidos por la escritura investigativa en la academia.

Gracias a este trabajo analéctico liberador, la co-autoría responsiva vendría a superar el carácter textualista (sin contexto) de una escritura que niega la presencia autorial del Otro y que desconoce el carácter de "exterioridad" propio del lenguaje escrito. Por la vía analéctica, el lenguaje recupera su carácter de respuesta abierta (inacabada) que siempre remite a un lenguaje-otro en un contexto-otro. Esta apertura del lenguaje -en las ciencias humanas y sociales- emerge cuando asumimos que hay una voz ajena (exterioridad) que "no está aquí conmigo", ciertamente, escribiendo; pero "sí está aqui" permitiendo el acontecer de la escritura. Es la otredad-distinta introyectada, presente en el diálogo interior de quienes investigan; pero que, a su vez, permanece como pura exterioridad que contribuye a forjar ese "estar aquí, escribiendo acerca de".

En estas circunstancias, la coautoría responsiva es un diálogo inacabado que encarna un devenir histórico, porque permanece irreductible para engendrar un lenguaje nuevo. A ello contribuye la ética analéctica, que exige tener $f e$ en otro concreto y activo que escapa a toda práctica totalizadora. En este sentido: "EI método ana-léctico surge desde el Otro y avanza dialécticamente: hay una discontinuidad que surge de la libertad del Otro. Este método, tiene en cuenta la palabra del otro como otro, implementa dialécticamente todas las mediaciones necesarias para responder a esa palabra, se compromete por la fe en la palabra histórica y da todos esos pasos esperando el día lejano en que pueda vivir con el otro y pensar su palabra" (Dussel 1995:236).

Según este planteamiento, la coautoría responsiva busca abrir el momento dialéctico de la escrituraautoría para evitar transformarse en un movimiento cerrado, totalizador. Para ello, redescribe la tensión escritural ("Estar Alli"- "Estar Aqui") como praxis abierta a esa exterioridad que escapa al lenguaje (escrito), pero que es presencia de una ausencia. En virtud de esta presencia, la escritura de la investigación social adquiere una significación que la aleja de la banalidad, del productivismo y del talento cerrado sobre sí. Solo la resonancia de esa exterioridad salva a la escritura investigativa del vacío, al darle el sentido de respuesta adeudada a un tercero (auto)excluido. Así, la autoría siempre es compartida con un tercero real y concreto, que interpela desde un lugar-otro exterior a la academia y a su escritura totalizadora; un Otro que ha sido localizado afuera del marco institucional y normativo de la totalidad hegemónica.

Desde la perspectiva analéctica liberadora, el problema ya no es construir una "continuidad textual" entre el "Estar Alli" y el "Estar Aqui"; sino co-construir un lugar de praxis-escritural desde donde la otredaddistinta irrumpe para mostrar las discontinuidades entre esos dos lugares. Se trata de unas co-escrituras y 
co-autorías de las ausencias de sentidos, que irrumpen e interpelan al "Estar Aqui" después de haber "Estado Alli". Ello es posible porque la analéctica liberadora es "una filosofía donde la conciencia asume su inevitable posición de ruptura" (González-San Martín 2014:51). Sobre este contexto, queda claro que cuando Geertz habla de una tensión entre el Estar Allí y el Estar Aquí, no alcanza a apreciar la voz del otrodistinto como interpelación. Si bien, en la tensión geertziana hay una preocupación por ser fiel a lo dicho por el otro, este aún es visto desde una posición autorial privilegiada, 'hegemónica', que solo busca ajustar/reformar la autoría establecida. Así, la crítica geertziana está centrada en la perspectiva de enunciación de los investigadores-autores y desde esta posición incorpora una ética que busca escribir la vida de los otros como 'asunto moral, política y epistemológicamente delicado'.

Por el contrario, la alternativa analéctica, para superar la tensión escritural entre el "Estar Alli" y del "Estar Aqui", es la irrupción del Otro y de la Otra como exterioridad en la escritura. En este sentido, dicha tensión puede postularse como parte (primer estadio) de un movimiento analéctico que busca abrir la autoría de las investigaciones sociales. Este movimiento operaría mediante coautorías responsivas que transforman la crítica cerrada de la autoría en apertura al poder-autorial de los 'sujetos-otros-conocidos'. Ello es posible, porque la exterioridad como campo de la analéctica permite redimensionar el trabajo de coautoría como trabajo liberador de temporalidades diversas.

Cabe precisar que estamos de acuerdo con Martín Retamozo cuando señala, refiriéndose al quehacer de las ciencias sociales críticas: "Asumir el punto de partida desde la negatividad del ser (como constitutivo) es una condición necesaria del pensamiento crítico pero no suficiente, se requiere, además, el tratamiento del criterio de verdad" (Retamozo 2017:341); "un arduo trabajo de producción y de fundamentación de un conocimiento válido, (...) ubicado en su politicidad, como parte de las luchas sociales por horizontes más justos" (Retamozo 2017:345). No obstante, pensamos que la escritura investigativa, en la trama aquí tejida, puede aportar en la construcción de coautorías que, efectivamente, puedan "mediar" en el "ascenso a lo concreto". En esta dirección, a su vez, debemos recordar que la ecología de saberes no es solo un asunto de 'equilibrio o justicia epistemológica', sino de un "posible diálogo de esos saberes 'epistemológicos' con aquellos otros conocimientos que no se denominan 'epistemológicos' ni les interesa ser reconocidos como tales" (Fornet-Betancourt 2018:325).

Desde este horizonte, la crítica a las autorías implica ir más allá del nombre propio; lo que Raúl FornetBetancourt, en una entrevista realizada el 2017, interpreta como "dejar de lado el concepto de autor, de autoría para ir más bien a un concepto comunitario de producción colectiva (...) ir por la línea de la creación de comunidades. (...) no por nombres que nos alumbren, sino por lugares muy locales" (González-Fuentes 2017:181). Este es un llamado a dejar de lado el cultivo del yo individualista y avanzar hacia una escritura colectiva que dé cuenta de que la investigación social es un trabajo dialógico con otros muy diversos. Por esta vía, la coautoría responsiva que proponemos pretende ser un aporte para superar la fractura cultural que los investigadores sociales tenemos con el "mundo de la vida".

\section{Conclusión}

Descolonizar la investigación de la diversidad sociocultural exige reconocer la coexistencia juegos de lenguajes que permanecen irreductibles a la escritura. En este sentido, situar el conocimiento es reconocer que siempre habrá un autor o coautor que escapa a la escritura: la otredad-distinta, voz extraña que se revela como presencia no presente en el texto (exterioridad). Frente a ello, la escritura-autoría deviene respuesta abierta (inacaba), respuesta adeudada a una otredad-distinta que es condición de posibilidad 
de la escritura. En efecto, si la escritura es constitutiva de investigaciones sociales que implican, activamente, a los "sujetos-otros-conocidos"; entonces, es necesario instituir el reconocimiento del poder autorial de la palabra ajena como valor epistémico-político articulador de escrituras investigativas.

En este sentido, la descripción densa -experiencia interpretativa inter-contextual entre el "Estar Alli" y el "Estar Aqui"- es un proceso holístico que sitúa la escritura-autoría como práctica inherente a la investigación. La descripción densa conforma una espiral hermenéutica que transita entre el todo y la parte, entre la cultura y el texto. En esta trayectoria, va generando intersticios para una escritura-autoría en co-labor. Desde estos espacios intersticiales puede fluir la exterioridad analéctica dusseliana que viene a descolonizar la tensión escritural propuesta por Geertz. Ello ocurre porque el diálogo-analéctico sitúa la autoría-escritura científica en un campo de conflictividad inter-contextual sensible a la exterioridad (otredad-distinta); que es la que impulsa a reconocer la autoría de la palabra ajena.

Sobre este contexto, la coautoría responsiva, aquí planteada, busca evitar la reproducción del falso reconocimiento que deforma la autoría de los 'sujetos-otros-conocidos'. Si la escritura-autoría es un acto ético-político inherente al interés liberador de las ciencias humanas y sociales; entonces, estas deberían tener como correlato una coautoría, cuyo carácter responsivo, en su doble acepción de respuesta y de responsabilidad, permitiera reconocer -en el espacio público- a los 'sujetos-otros-conocidos' como autores. En este sentido, el diálogo entre descripción densa, tensión escritural y analéctica, da lugar a una co-autoría responsiva que potencia una praxis escritural liberadora, porque necesita crear algo nuevo que, efectivamente, responda al poder interpretativo-autorial que emerge desde la otredad-distinta.

\section{Bibliografía}

Bajtín, M. (1997). Hacia una filosofía del acto ético. De los borradores y otros escritos. Anthropos.

Bajtín, M. (1999). Estética de la creación verbal. Siglo XXI editores.

Bajtín, M. (2015). Yo también soy (fragmentos sobre el otro). Ediciones Godot.

Binimelis-Espinoza, H., Roldan-Tonioni, A. (2017). Sociedad, epistemología y metodología en Boaventura de Sousa Santos. Convergencia 24(75): 215-235.

http://www.scielo.org.mx/scielo.php?script=sci arttext\&pid=S1405$14352017000300215 \& \operatorname{lng}=e s \& n r m=i s o$

Bubnova, T. (2006). Voz, sentido y diálogo en Bajtín. Acta Poética 27(1): 99-114. https://doi.org/10.19130/iifl.ap.2006.1.191

Costilla, M. (2010). La antropología y el sentido. Tópicos del seminario 23: 291-329. http://www.scielo.org.mx/scielo.php?script=sci arttext\&pid=S1665$12002010000100009 \& \operatorname{lng}=e s \& n r m=i s o$

De la Peza, M.C. (2012). Horizontalidad, diálogo y reciprocidad en los métodos de investigación social y cultural: Retos y perspectivas. En: M. Pérez-Daniel, S. Sartorello. Horizontalidad, diálogo y reciprocidad en los métodos de investigación social y cultural, pp. 153-157. Universidad Autónoma de Chiapas.

Dussel, E. (1995). Introducción a la filosofía de la liberación. Editorial Nueva América.

Dussel, E. (2011). Filosofía de la liberación. FCE. 
Dussel, E. (2014). 14 tesis de ética. Trotta.

Escobar, A. (2011). El lugar de la naturaleza y la naturaleza del lugar: ¿globalización o postdesarrollo? En: E. Lander. La colonialidad del saber: eurocentrismo y ciencias sociales, pp. 131-161. CICCUS, CLACSO.

Fornet-Betancourt, R. (2018). Del conocimiento teórico contemplativo al saber dominador y destructor. Valenciana 21: 323-346. https://doi.org/10.15174/rv.v0i21.361

Gadamer, H-G. (2003). Verdad y método I. Ediciones Sígueme.

Gadamer, H-G. (2004). Verdad y método II. Ediciones Sígueme.

Gambarotta, E. (2014). Discusiones epistemológicas acerca de la reflexividad en sociología: Adorno, Bourdieu y una propuesta con base en la teoría crítica reflexiva. Acta Sociológica 64: 9-34. https://doi.org/10.1016/S0186-6028(14)70481-5

Geertz, C. (1994). Conocimiento local. Paidós.

Geertz, C. (1996). Tras los hechos. Dos países, cuatro décadas y un antropólogo. Paidós.

Geertz, C. (1997a). La interpretación de las culturas. Gedisa.

Geertz, C. (1997b). El antropólogo como autor. Paidós.

Gómez, C. (2015). La hermenéutica intercultural de Raimon Panikkar. Franciscanum 57(164): 19-43. http://www.scielo.org.co/scielo.php?script=sci arttext\&pid=S0120$14682015000200002 \& \operatorname{lng}=e n \& n r m=$ iso

González-Fuentes, L. (2017). La creación de saberes y su correlato político: urgencias y desafíos en la gestación de un conocimiento transformador. Hermenéutica Intercultural 27: 171-187. https://doi.org/10.29344/07196504.27.497

González-San Martín, P. (2014). La filosofía de la liberación de Enrique Dussel. Una aproximación a partir de la formulación de la analéctica. Estudios de Filosofía Práctica e Historia de las Ideas 16(2): 45 52. https://dialnet.unirioja.es/servlet/articulo?codigo $=5718860$

Leyva, X., Speed, S. (2008). Hacia la investigación descolonizada: nuestra experiencia de co-labor. En: X. Leyva, A. Burguete, S. Speed. Gobernar (en) la diversidad: experiencias indígenas desde América Latina. Hacia la investigación de colabor, pp. 65-107. CIESAS-FLACSO.

Malik, B., Ballesteros, B. (2015). La construcción de conocimiento desde el enfoque intercultural. Diálogo Andino 47: 15-25. https://doi.org/10.4067/S0719-26812015000200003

Mansilla-Torres, S. (2013). “¿Qué es un autor?” ... A la luz de las poéticas del subalterno. Estudios filológicos 51: 39-53. https://doi.org/10.4067/S0071-17132013000100004

Monteagudo, C. (2013). El descentramiento del sujeto en la experiencia interpretativa. Summa Humanitatis 6(2): 2-22.

http://revistas.pucp.edu.pe/index.php/summa humanitatis/article/view/7484

Panikkar, R. (2002). La interpelación intercultural. En: G. González, R. Arnaiz. El discurso intercultural. Prolegómenos a una filosofía intercultural, pp. 23-73. Biblioteca Nueva.

Panikkar, R. (2007). Mito, fe y hermenéutica. Herder. 
Retamozo, M. (2017). Epistemología de las ciencias sociales en la filosofía de la liberación de Enrique Dussel. Cinta moebio 60: 339-345. https://doi.org/10.4067/S0717-554X2017000300339

Ricoeur, P. (2001). La metáfora viva. Editorial Trotta.

Rivera-Cusicanqui, S., Domingues, J., Escobar, A., Leff, E. (2016). Debate sobre el colonialismo intelectual y los dilemas de la teoría social latinoamericana. Cuestiones de sociología 14 e009:1-22 https://www.cuestionessociologia.fahce.unlp.edu.ar/article/view/CSn14a09/7368

Sáez-Rueda, L. (2009). Movimientos filosóficos actuales. Editorial Trotta.

Sánchez-Melero, H., Gil-Jaurena, I. (2015). Análisis interseccional y enfoque intercultural en el estudio de la ciudadanía y la participación: consideraciones epistemológicas. Diálogo Andino 47: 143-149. https://doi.org/10.4067/S0719-26812015000200015

Santos, B. (2005). El milenio huérfano. Ensayos para una nueva cultura política. Trotta.

Santos, B. (2006). Renovar la teoría crítica y reinventar la emancipación social. CLACSO.

Santos, B. (2010). Para descolonizar occidente: más allá del pensamiento abismal. CLACSO.

Santos, B. (2011). Epistemologías del sur. Utopía y Praxis Latinoamericana 16(54): 17-39. http://produccioncientificaluz.org/index.php/utopia/article/view/3429.

Valenzuela, C. (2014). Por una escritura situada en el ámbito de la investigación social. Enunciación 19(1): 103-111. https://doi.org/10.14483/udistrital.jour.enunc.2014.1.a08

Vasilachis de Gialdino, I. (2006). Estrategias de investigación cualitativa. Gedisa.

Waldenfels, B. (1997). Respuesta a lo extraño. Rasgos fundamentales de una fenomenología responsiva. Daimon 14: 17-26. https://revistas.um.es/daimon/article/view/9111

Waldenfels, B. (2017). Fenomenología de la experiencia en Edmund Husserl. Areté 29(2): 409-426. https://doi.org/10.18800/arete.201702.008.

Weiss, E. (2017). Hermenéutica y descripción densa versus teoría fundamentada. Revista mexicana de investigación educativa 22(73): 637-654. http://www.scielo.org.mx/scielo.php?script=sci arttext\&pid=S1405$\underline{66662017000200637 \& \operatorname{lng}=e s \& n r m=i s o}$

Recibido el 22 Nov 2019

Aceptado el 5 Ene 2020 